\title{
Aportaciones coloniales a las creencias funerarias ibéricas
}

\author{
Joaquin Garcia Raya
}

\section{RESUMEN}

La "mediterraneidad" de la península ibérica ha producido una serie de contactos con otros pueblos de esta cuenca, atraidos por su riqueza minera o como recurso a la colmatación de sus territorios de origen, lo cual produjo una traslación de ritos funerarios, cuya lectura arqueológica ha significado interpretaciones erróneas básicas.

\begin{abstract}
The "Mediterranean style" of the Iberian Peninsula has given way to a series of contacts wth other peoples fron this valley, attracted by its mining richness and as an option tgo the overcrowding of their native territories. This brought about the implantation of funeral ceremonies, who archaelogical reading has meant false interpretations.
\end{abstract}

\section{INTRODUCCIÓN}

El territorio de la Península Ibérica, situado en el extremo occidental del continente europeo, es, al mismo tiempo, vía de comunicación entre Europa y África, junto a puerta emblemática del Mar Mediterráneo. Esta localización periférica, respecto a los focos culturales/tecnológicos, no significó un alejamiento de las evoluciones culturales que se venían produciendo en el área circunmediteránea. Todo lo contrario. Pues, junto a las mejores exhibiciones de arte parietal paleolítico, concentrado sobre todo en la Cordillera Cantábrica (como prolongación, que no apéndice, del producido en la vertiente septentrional pirenaica) ${ }^{\prime}$, observamos como otras manifestaciones

Dentro del conjunto de arte parietal que presenta esta cordillera, se puede destacar Altamira, aunque las muestras abarcan a casi la totalidad de las divisiones que del arte parietal realizó LEROI-GOURHAN. 
posteriores encuentren su posible génesis en este territorio. Estas expresiones culturales (megalitismo, vaso campaniforme), indican ya unas relaciones humanas entre puntos muy alejados geográficamente, aunque no insalvables, para los medios de comunicación existentes.

Dicha comunicación intercomunitaria nos es útil para ponernos en relación con posibles movimientos migratorios o comerciales; ya que una característica tradicional de la Península lbérica es ser lugar de cruces étnicos y culturales, puestos más en relieve cuando las diversas culturas exógenas a la Península, tienen como fin las riquezas del subsuelo peninsular, como ponen en relieve F. Presedo y otros autores (J. Santos), al hablar de la extraordinaria importancia que tuvo la minería para comprender el proceso de colonización habido en la Península.

Esta característica colonial si bien es cierto puede servir para casi la totalidad de la zona meridional, bien como resultado de la explotación de los recursos del subsuelo o como factorías costeras y enclaves internos con una función defensiva de las rutas comerciales (o sea, el valle del Guadalquivir, junto al aprovechamiento de los cursos fluviales en sentido perpendicular a este río). Tampoco debe olvidarse un origen de colonización demográfica desde las zonas del Mediterráneo oriental, cuyos ejemplos en la zona central de este mar son un buen ejemplo.

Estas aportaciones exógenas, tanto si llevan una intencionalidad económica, como si se produjo por una sobrepoblación en sus lugares de origen, fueron motivadas por las relaciones entre pueblos indígenas y colonizadores, llevaron a diversas formas de sincretismo; dependiendo, a grandes rasgos y de forma general, de la ratio potencia cultural aborigen/exógena. Una de las principales manifestaciones culturales es el ambiente religioso, pues como bien señala Luis Maldonado en su estudio sobre la religiosidad popular, todo to que tiene un sentido y alude «a la realidad absoluta", para el hombre de sociedades preindustriales posee una connotación de valor sagrado. De esta manera nada escapaba a lo sobrenatural.

\section{PRINCIPALES FUENTES PARA EL MUNDO FUNERARIO IBÉRICO}

Para interpretar la religiosidad de los pueblos de la zona ibérica, partimos de los restos arqueológicos conectados con el mundo funerario y de las esculturas de los santuarios (tenidos como ex-votos). Junto a estas fuentes encontramos otras como las literarias y numismáticas; aunque estas dos fuentes significan la implantación de la cultura colonizadora o la 
adaptación teónima por parte de los colonizadores en un primer momento, surgiendo posteriormente la «interpretatio" latina. Por lo tanto, para averiguar si hubo esa coexistencia de elementos religiosos con diverso origen cultural, o sea, sincretismo, es más fácil de averiguar en los restos arqueológicos; mayoritariamente a los que hacen referencia al mundo funerario, sin olvidar otras manifestaciones. Sin embargo, estas fuentes mostraban, hasta muy recientemente, el problema de su aparición fuera de su contexto arqueológico, lo cual dificultaba cualquier posible interpretación. Un claro ejemplo de lo que estamos comentando son los relieves de Osuna, de gran valor por ser de las últimas manifestaciones culturales ibéricas, además de observar la evolución de los monumentos funerarios; fueron localizados en la muralla de Urso, levantada por los enemigos de Cesar durante la Guerra Civil y, por tanto, seguidores de Pompeyo. Hasta las apariciones de la torre de Pozo Moro, de la Dama de Baza y de las esculturas de Porcuna, el mundo funerario ibérico no tenía una base suficientemente sólida sobre la cual ofrecer una interpretación a los numerosos restos escultóricos, los cuales, hasta esos momentos sólo disponían de interpretaciones conjeturables.

\section{MUNDO FUNERARIO IBÉRICO}

Una de las características de la religión ibérica, puesta en relieve por casi todos los investigadores que han abordado el tema, es su proyección hacia la naturaleza. Esta característica de la religiosidad ibérica común a otras religiones antiguas, la vemos perdurar incluso más de un milenio, como bien señala Marc Bloch en su obra sobre la sociedad feudal ${ }^{2}$. Las limitaciones tecnológicas hacían necesarias la convivencia muy directa del ser humano con su medio natural, extremadamente dependiente de los elementos naturales; de igual forma, su escasa supervivencia le hacía extremadamente práctico, buscando un beneficio terreno más que experimentar sensaciones salvíficas; esto no quiere significar que poseyera sólo nociones terrenales. Pues, como se demuestra con el mundo funerario, existe una elaboración perfectamente calculada desde su integración con la naturaleza y sus ciclos. Por lo tanto, el hombre de las culturas preindustriales, ante la concreción de la muerte como separación radical de la vida, elabora diversos mitos y recurre a gestos rituales (o "artefactos", como los pudo perfectamente definir Malinowxki), cuya función no es otra que la regeneración, tomados de los ciclos agrícolas o lunares; permitiendo, de esta

2 Marc BLOCH. La sociedad feudal, pág. 84 (Madrid, 1986). 
manera, la idea cíclica del mundo en alternancias antitéticas como vida, muerte y renacimiento tras la muerte, descubriendo, con este ciclo, la unidad fundamental de ambos conceptos, aunque desde perspectivas dramáticas perfectamente rastreables en los mitos de Atis, Osiris, Tammuz, en cuanto que son muertes violentas.

Los lugares de enterramientos se disponían a extramuros de las poblaciones, como se observa en Cástulo,que, debido a su prolongada ocupación, conserva diversas necrópolis, observando todas la misma localización respecto al poblado; posiblemente referido a una causa de purificación del recinto urbano. Excepciones a estos lugares de enterramiento serían los de niños con escasa edad, en la mayoría de los casos no alcanzan los dos años, cuyo lugar de enterramiento hay que situarlo en el interior de las viviendas, en concreto se hace referencia a los muros. Dicha localización no debe hacernos pensar en sacrificios rituales y sí que la corta edad de los fallecidos, que van desde los nonatos hasta casi lejos dos años, se tuvieran como seres no incorporados a la comunidad y, por lo tanto, sin derecho a ser enterados en las necrópolis colectivas; utilizándose el recurso de enterramientos domésticos. ${ }^{3}$ Ante este planteamiento, diversas comprobaciones se pueden aducir: enterramientos argáricos (aunque en este caso no se logró determinar la edad), también esta localización se conoce para el enterramiento de un niño en el Herault, datado en siglo IV a. de C.; pero una argumentación más cercana en el tiempo, aunque con un significado muy próximo, es la costumbre vasca de enterrar a los niños muertos no bautizados no en los cementerios y sí en los ámbitos domésticos, en concreto, debajo de los aleros de la casa. La elección del muro habría que ponerlo en relación con la facilidad que dicho elemento permite señalizar la localización del enterramiento y no ser estorbo para el paso, como sería si el enterramiento se produjese en el centro de la estancia.

Lo que sí debe ponerse en relación con rituales son las orientaciones de dichos enterramientos, que en el caso de la Romana guardan un sentido SW-NE, lo mismo podemos señalar para la necrópolis de Estacar de Robainas, tanto de los enterramientos como del lugar donde se producía la incineración de clara significación solar. Esta misma orientación encontramos en la necrópolis de El Cigarralejo (Murcia); donde también existe una diferenciación sexual y económica en los ajuares, no muy tajante en el primer caso, pero sí en las diferenciaciones económicas con cerámica ática, entre otros elementos, por lo que es posible entender que estos productos elaborados fueran tenidos como instrumento de intercambio por

\footnotetext{
Miguel Beltrán Lloris. El poblado ibérico de Castillejo de la Romana (Madrid, 1979).
} 
materias primas que controlasen las élites locales; diferenciadas en las proporciones de sus recintos mortuorios, al menos en El Cigarralejo, donde por vez primera se estudió una necrópolis mediante un análisis sociológico: frente a una superficie de los túmulos entre 1 y $10 \mathrm{~m}^{2}$; existen dos túmulos con una superficie cercana a los $36 \mathrm{~m}^{2}$ y aisladas en el extremo Este de la necrópolis.

El difunto sufría una serie de ritos antes, durante y después de su cremación. En este primer paso el fuego jugaba un importante papel. Vestido con su mejor indumentaria, joyas y armas, si pertenecia en este último caso a la casta guerrera, era depositado en la pira funeraria, ubicada en lugar distinto y destinada para esta función, pero que ya hemos visto, con una orientación del recorrido solar. Aquí habría preguntarse si también existía un momento preciso para la cremación: ¿alba u ocaso?; el ritual funerario de Patroclo empezó al alba (lliada, XXIII,48). El suelo, donde se depositarían las cenizas, también sufría la acción del fuego. Como observamos, el fuego es utilizado con un sentido más de purificar que otro motivo. Seguidamente podía llevar dos procesos: bien se le separaban los huesos de las cenizas, lavándolos y depositándolos en una urna, mientras que las cenizas se arrojaban a un pozo excavado para tal uso; el otro proceso era que todo lo quemado se colocase directamente sobre el suelo preparado como arriba indicamos o bien por una capa de arcilla, adobe o piedra, cerrando el hueco de igual forma.

Durante este ritual también se producía el sacrificio de determinados animales; algunos pueden entenderse para la comida ritual posterior; sin embargo, la aparición de restos óseos de caballos o perros o en concreto en los enterramientos infantiles del poblado ibérico de Castillejo de la Romana (Teruel), con restos óseos de pájaros, liebres oconejos con su simbología de goce del más allá, parece más como acompañamiento o de expresar un deseo.

De igual forma la aparición de diversa cerámica ática y en concreto los "kylikes" parecen indicar consumo de vino, lo que explicaría las escenas dionisiacas pintadas en los vasos, a parte de su significación fúnebre. Este vino sería una parte importante del banquete funerario, tanto por su consumo como por las libaciones hechas en honor del difunto, donde se consumía abundante comida y bebida, ésta se consumía en unos vasos que posteriormente se estallaban contra la pira funeraria. Junto a este banquete se utilizaban pebeteros para perfumar el cuerpo del difunto antes de depositarlo en la pira y también se quemaban perfumes en el momento de depositar las cenizas en el túmulo. Ambos rituales debemos ponerlos en relación con las tierras añadas por el Mediterráneo Oriental. 
También es de destacar la aparición en las excavaciones de diversas tumbas "vacías" en su totalidad, que J. M. Blázquez apunta en la dirección de que funcionasen a manera de cenotafios; dando a entender, siguiendo la literatura homérica ${ }^{4}$, que el suceso más terrible en los pueblos de cultura circunmediterránea era, una vez muertos, no tener todo el ritual funerario, incluido la colocación de las cenizas en su lugar correspondiente. En los momentos anteriores de su muerte, Hector se dirige a Aquiles, rogando que su cadáver sea entregado a sus padres para que le den sepultura, siguiendo el ritual funerario, en cambio Aquiles, lleno de ira por la muerte de su amigo Patroclo, lo deniega, vengando de esta manera la muerte de éste.

La cremación y el depositar las cenizas en la tierra, contrasta con el rito llevado a cabo por los pueblos indoeuropeos peninsulares, quienes dejaban a sus guerreros sin enterrar, para que sus despojos fuesen comidos por los buitres. Dicha distinción nos lleva a concepciones funerarias distintas: el vuelo del buitre nos indica espacialmente hacia el cielo (concepción religiosa astral), mientras que los pueblos mediterráneos, al enterrar sus muertos, la vida de ultratumba se desarrolla en contacto con la tierra, propio de sociedades predominantemente agrícolas que han llevado un acto de perduración conceptual de dioses ctónicos, como revelan los mismos ritos eleusianos.

Esta necesidad de dar el último cobijo, aunque a veces sea de forma sólo simbólica, quizás tenga el sentido de la vuelta a la tierra, que es la madre, donde se aprecia una asociación "Materia-Madre", que posiblemente vemos en la representación de esas esculturas sedentes femeninas de las culturas circunmediterráneas.

Cada persona, como señalamos más arriba, era enterrada con ajuares $u$ ofrendas muy específicas de su condición. Así los niños en Castillejo de la Romana, aparecen con diversos animales mientras que los ajuares de armamento habría que ponerlos en relación con un fenómeno que desde el siglo vII a. de C., se aprecia en los ajuares funerarios, por un lado, el progresivo enriquecimiento de algunos ajuares, manifestado por la aparición de cerámica griega y la abundante presencia de armas, lo que nos está indicando el aumento de una jerarquia de claro significado bélico (cascos, pectorales metálicos). Esta aparición del componente aristocrático militar no

4 Los ejemplos son numerosos en la lliada, aunque destacan quizás por encima de todos y đebido a un sentimiento universal, con auténtica función expresiva, los ruegos dirigidos por la madre y el padre de Héctor a ésta para hacerle regresar dentro de las murallas y desprecie el combate con Aquiles (XXII,82). 
es extraño en el mundo mediterráneo: la Grecia geométrica o el período viIloviano itálico conocen un poco antes (ss. VIII/VII a. C.), la aparición de dicha aristocracia armada, reconocida,pues se entierran con carros o bocados de caballos. Dicho retraso cronológico parece poner en relación de dependencia ibérica directamente ideológica con las sociedades predominantes del Mediterráneo; aunque no debe olvidarse que esta evolución puede efectuarse de forma interna, sin que el componente exógeno sea fundamental, sino habría que verlo más como un incentivo.

En la necrópolis ibéricas no faltan estas armas, bien como distintivo de importancia militar, otras veces económicas (si es posible deslindar dichas facetas), con el armamento ibérico clásico: la espada recta y corta, cuyas dimensiones escasamente alcanzan los $40 \mathrm{~cm}$. y empuñaduras adornadas con diversos materiales; la procedencia mesetaria nos pone en relación ambos ambientes peninsulares (el mesetario y el ibérico). Dichos contactos se refuerzan con la aparición en este ambiente ibérico, de puñales con antenas atrofiadas de la denominada Cultura de las Cogotas; por ejemplo en la cámara de Toya o con las armas aparecidas en Obulco y que el profesor Antonio Blanco Freijeiro no dudó de dar una procedencia mesetaria. Pero junto a estas armas originarias de la Meseta, aparecen las propias del mundo ibérico, como la falcata, cuya longitud es algo mayor que la anterior (de 50-60 cm. sin empuñadura) y con forma curva. Además se encuentran puñales de hoja triangular, "falaricas", regatones y las «soliferrea"; en cuanto a armas defensivas han aparecido preferentemente las manillas del escudo. Todos estos ajuares bélicos eran quemados la mayoría de las veces con el cadáver, quizá con la intención de que acompañaran al difunto, como objeto muy personal, explicando así que previamente habian sido dobladas, inutilizándolas ritualmente.

Ante lo expuesto no es extraño que $F$. Presedo hable del continuo reflujo religioso de griegos y fenicios sobre la población indígena ibérica.

Todos estos monumentos, los cuales inmediatamente pasamos a dilucidar, nos han llegado destruidos, sin conservarse "in situ", salvo el de Pozo Moro. Expresión de la violencia de una sociedad que desarrollaba unas nuevas formas de relaciones intra e intertribales que producía tensiones; las cuales, muchas veces, acabarian violentamente y que se cebarían en estos monumentos, incluso en algunos de estos con auténtica saña y cuyo significado es fácilmente conjeturable: dichos monumentos se verían como la manifestación de unas élites controladoras y beneficiadas económicamente de los intercambios comerciales con las sociedades que tuvieron a la península como fuente de materias primas. Pero además nos permite conjeturar que estos monumentos no son sólo meros soportes 
de enterramientos, sino "consagraciones a la memoria» (Ballart, Josep. 1997); permitiendo una vinculación real con el pasado y del individuo con el grupo que mantiene también esa relación.

\section{EVOLUCIÓN DE LAS INFLUENCIAS EXÓGENAS EN LAS CREENCIAS FUNERARIAS}

Antes de entrar a analizar los diversos aportes exteriores, sobre todo aquellos que más se pueden caracterizar de procedencia exógena en los ritos funerarios, se hace necesario hablar del monumento turriforme como sujeto propio de valor simbólico.

Toda representación arquitectónica desde sus inicios hasta muy recientemente ha pertenecido a dos planos. Uno, que hacia referencia al plano constructivo y otro de clara significación simbólica. El primero se consagraría a la parte material de la construcción (cimentación, materiales,los diversos cálculos necesarios para la elevación de la construcción), mientras que la segunda la podríamos considerar como metaarquitectónica. La existencia de esta última es tan implícita tanto como la primera y cuyos ejemplos se han prolongado hasta muy recientemente y para explicarlo no hace falta retrotraerse mucho: $¿$ a quién se la escapa la colosidad faraónica de los Nuevos Ministerios, o el rigor escurialense del edificio destinado en su momento al Ministerio del Ejército del Aire?

La elevación de monumentos funerarios sobre el territorio es común a toda cultura, como muestra de fijación de un "hito" geo-comunitario (ambas características se desarrollan más adelante, en concreto, cuando hablemos del significado de los monumentos funerarios turriformes). Dicho fenómeno no es extraño a la península Ibérica. En este marco geográfico y según las dataciones absolutas, encontramos las primeras manifestaciones de este movimiento espiritual, conocido como megalitismo, pues la génesis se halla en el interior de los individuos, quienes, mediante estas obras, intentan plasmar unos sentimientos comunes. Dichas manifestaciones con datación absoluta obliga a rechazar el difusionismo oriental defendido por V. G. Childe.

Las características de estos movimientos megalíticos se ajustan perfectamente a los posteriores monumentos que irán apareciendo por las siguiente páginas: la necesidad voluminosa de horas para la elevación de estos monumentos hacen de ellos un punto de referencia étnico, espiritual y económico. Étnico: en cuanto hace referencia a un grupo concreto, dominador de un territorio, guardando relación con los hitos dolménicos, 
mientras que la seña de identidad tribal se identificaría mediante la incorporación a lo que podemos denominar como la referencia espiritual, la cual se presenta en la intención de perpetuarse con una obra intemporal, por encima de la corta vida humana; por esto, podemos tomar perduración como negación de la misma muerte, apoyada por la simbología iconográfica de los relieves que presentan estos monumentos; pero, al mismo tiempo, es también la identificación de ese personaje ahí enterrado y es conseguir la inmortalidad más arriba indicada, pues sus cenizas depositadas consiguen categoría sobrehumana mediante la construcción de edificios tan magnificantes (esta categoría se acrecenta si se compara esta vivienda de ultratumba con la poseída en la vida terrenal, levantada con paredes de adobe y tejados de origen vegetal, o sea materiales endeble y, por tanto, perecederos), pues ayudaría a perdurar al menos su memoria 5 ; permitiendo la identificación de la comunidad descendiente hacia el recuerdo de ese individuo, mediante la contemplación de dicha morada y de relieves que por lo general representan al difunto heroizado. Esta identificación comunitaria permite recuperar la parte terrenal: el impresionante coste económico de estos monumentos en beneficio de un determinado personaje o, en su caso, de algún linaje, lleva a la aparición de una diferenciación social muy marcada, mediante la apropiación de los excedentes productivos, cuya causa principal, sin duda, se produce por aparecer una determinada especialización productiva del trabajo. Esta apropiación utilizada para la deposición de las cenizas llevan a identificar rito funerario en beneficio de un individuo con una identificación comunitaria cuyo beneficio, quizá, se buscase de tener un representante apotropaico, pues en las religiones antiguas aparece una necesidad colectiva que no es otra que asegurar la continuidad del grupo, función que encuentra su paralelo egipcio en la regeneración que sufría el faraón. La saña sufrida por estos monumentos en su destrucción pudiese corroborar esta hipótesis: al destruir estos monumentos, además se buscase la destrucción total de un "mojón" tribal en el sentido de que existiese una identificación comunitaria con dichos monumentos; de ahí también el posterior "mimo" de preservar los restos. Sin esa identificación comunitaria, se hace difícil entender estos casos intencionados por querer preservar dichos restos. La aparición tardía de los restos de monumentos funerarios significó una reinterpretación del mundo ibérico, sobre todo en lo que se refiere a su religiosidad y, más en concreto, a las posibles incorporaciones al acervo religioso ibérico por parte de los colonizadores.

\footnotetext{
5 Más arriba se ha aludido a la expresión "consagraciones a la memoria" que Jossesp BALLART utiliza en su libro: "El partrimonio histórico y arqueologico: valor y uso" (Barcelona, 1997).
} 


\section{Influencia oriental}

El primer conjunto al que es obligado hacer referencia es el monumento turriforme que en 1971 fue descubierto por M. Almagro Gorbea, el cual, por el ajuar cerámico encontrado en su interior es posible fecharlo entre los siglos $\mathrm{vI}$ al $v$ a. C. Este monumento, hoy expuesto en el Museo Arqueológico Nacional, se compondría de tres cuerpos. Primero, una escalinata de tres gradas con un segundo cuerpo donde una línea de sillares con cuatro leones-sillares en las esquinas, permite desarrollar una altura de cinco sillares con una decoración en relieve, coronado por un cornisamento donde irían otros cuatro leones en la misma posición con otros relieves, todo esto coronado por una construcción en forma de pirámide; por lo cual, la reconstrucción que se observa en este monumento alcanzaría algo más de la mitad de su altura.

La decoración escultórica se compone de leones-sillares y de diversos relieves que nos ponen en contacto con un mundo lejano, tanto espacial como temporalmente. Vayamos por partes. Estos leones-sillares puestos en las esquinas con sus rasgos corporales muy bien dibujados, a los que volveremos más adelante, no pueden hacernos desviar la función que poseian, la cual no era otra que la defensa de la tumba y el descanso del muerto; esta función apotropaica se completaría en cuanto a representar el valor del difunto, junto a otro significado de continuo renacimiento (éste de procedencia egipcia). Valor y continuo renacimiento pudo ser fácilmente asimilable por las diversas monarquías que componían el mundo ibérico. Ahora regresemos a esos rasgos estilísticos: mandíbulas abiertas, colmillos superiores e inferiores unidos formando unas columnillas, orejas lanceoladas y aplastadas contra el cráneo, ferocidad lograda mediante las escisiones alrededor del hocico y la misma función estructural del sillar esquina, con una prolongación en el arte ibérico, nos lleva a rasgos claramente sirio-hititas, que en Amrit aún se conservan «in situ», ofreciendo el mejor paralelo a nuestro monumento funerario.

Esta procedencia orientalizante se ve reforzada por la interpretación iconográfica de los relieves: Simposion de ultratumba, Árbol de la Vida, una copulación entre un hombre y un ser con apariencia deífica, pues se encuentra deteriorado, presentando así un carácter de iniciación, escenas mitológicas de lucha, parte trasera de un tritón, centauros y un relieve muy importante: la figura de un ser con grandes alas desplegadas, sentado de frente, sujetando flores con las manos y pájaros posados en aquellas. Esta última descripción permite encontrar un paralelo en los bronces del Berrueco (Salamanca), donde se representa a la diosa Astarté con los mismos atributos, los cuales se fechan hacia el siglo vII a. C. De igual 
forma, Astarté es la diosa de la fecundidad y protectora del descanso del difunto. Estas dataciones tan altas no deben de sorprendernos, pues en el Cerro de la Galera, cuyo corte estratigráfico IX, dio un fragmento de cerámica elaborada mediante la técnica de retícula bruñida de procedencia orientalizante, junto a una elaboración mediante torno, se la da una cronología correspondiente al Bronce III pleno (800-700 a. de C.).

Todo lo visto nos lleva a una estrecha vinculación de la iconografía funeraria ibérica con el mundo oriental (sirio-hitita), transmitida por los fenicios. Esta conexión con el mundo de oriente todavía encuentra una relación más estrecha al recordar el tesoro de Aliseda, elaborado con un fin exclusivamente funerario, con temas de la recuperación de la vida tras la muerte, o sea, el triunfo sobre la muerte, como lo ponen en evidencia el teónimo de Isis en el jarrito de vidrio tallado (recuérdese que es ella quien, con su llanto, logra la resurrección de Osiris en forma del ciclo anual), junto al tema de Gilgamesh o de Melkart/Heracles, como dios de la fecundidad, el cual muere y renace cada año, paralelo fenicio de Osiris). Aunque esta referencia nos aparta del tema tratado, pues el tesoro se data en el último cuarto del siglo vII a. C., a los comienzos del siglo vi a. C., la pertenencia específica a un ritual funerario nos permite considerar que en la Península Ibérica (en el caso del tesoro de Aliseda, Tartessos), el componente religioso oriental era perfectamente asumido por las élites, quienes controlaban la distribución y comercialización económicas de la producción.

Parecidas características estilísticas y técnicas poseen otras obras del arte ibérico (León de Baena, Toro de Porcuna), ambas relacionadas con el mundo funerario; lo mismo que la cabeza de león procedente de la necrópolis de La Joya (Huelva), cuya función como cubo de un carro suntuario permite asentar el valor iconográfico de este animal.

\section{Influencia griega}

El descenso hasta la nulidad de contactos con Oriente y su sustitución por la influencia fócea, lleva a que dicha influencia se proyecte en las creencias religiosas y muy particularmente en las de carácter funerario, plasmándose de forma arqueológica en la aparición de nuevos elementos iconográficos. Algunos autores ponen la batalla de Alalia (535 a.C.), como el inicio de este proceso de transformación habido en estas relaciones comerciales; si bien, no debe olvidarse que las culturas desarrolladas alrededor del Mar Egeo eran ya conocidas por las élites ibéricas desde mucho antes. Donde el mundo iconográfico oriental parece ser sustituido por otro 
proveniente del mundo griego, más concretamente focense, el cual queda definido por el profesor Manuel Bendala de la forma siguiente. "Tras la brutalidad del relieve anterior (hace referencia al macabro banquete de uno de los relieves de Pozo Moro), una nota de sosiego". Dicha nota no será tal, como pronto apreciaremos. Esta incorporación iconográfica, sin embargo, no retira del todo las anteriores formas, como se aprecia en la Pátera de Santiesteban del Puerto ${ }^{6}$, o los bronces de Maquiz, estilísticamente muy cercanos.

El cambio de influencias producido no sólo afectó a los intercambios comerciales. La religión ibérica y, en concreto, los ritos funerarios muestran esta característica al presentar unas nuevas formas iconográficas, paralelas a la atracción que tuvieron las élites ibéricas hacia la cultura material griega, cuya penetración penínsular atestigua la llegada de nuevos elementos iconográficos, como grifos y esfinges que indican nuevas formas de creencias. Sin embargo, el conjunto que más claramente permite apreciar esta nueva mentalidad con relación hacia los ritos funerarios, se puede observar en las esculturas encontradas en el Cerrillo Blanco de Porcuna (la antigua Obulco).

En este lugar de la provincia de Jaén y durante las diversas campañas de excavación habidas entre 1975 y 1979, se catalogaron 1.288 piezas, restos escultóricos de lo que para muchos corresponde a un "heroon", para otros, en cambio, la violencia de la mayoría de las escenas lo alejan de este significado, como A. Blanco Freijeiro, quien lo define como un mausoleo.

El posible significado funerario se hace difícil, pues casi toda la escultura ibérica aparece descontextualizada, debido, en buena parte, a la destrucción intencionada que se puede observar en casi toda ella y cuyo ejemplo más interesante y numeroso es este conjunto de Obulco.

Ivan Negueruela los agrupa en varios grupos: escenas bélicas humanas con clara diferenciación entre vencedores y perdedores, sin ahorrar patetismo ni crueldad; figuras humanas no guerreras, con la posibilidad de que algunas de estas tuviesen carácter divino, entre las figuras humanas destacan los altorrelieves de los cazadores; también aparecen la lucha entre animales (destacando compositivamente el grupo del lobo devorando a una oveja) y la lucha entre figuras humanas y animales, ya reales 0 míticos.

- Sobre esta Pátera existe un estudio muy pormenorizado por Beatriz DE Griñó y Ricardo Olmos (M. A. N., Madrid, 1982). 
La posible interpretación habría que ponerla como una construcción de uso funerario, cuyo personaje principal tuviese carácter militar (escenas bélicas), junto a una heroización (escenas de lucha hombre-animal). Dicho uso funerario del posible "heroon", al cual pertenecerían estas esculturas, se refuerza con las escenas de caza, cuyo significado funerario era conocido en todo el Mediterráneo; de igual forma, el grupo escultórico reconocible de un lobo matando a un cordero tuvo una continuación funeraria posterior; o la posible interpretación de la Gripomaquia como una adaptación de la lucha entre el héroe y el león también de claro significado funerario, esta interpretación se apoya en la existencia de urnas funerarias, cuyo motivo principal de decoración es la figura de un grifo ${ }^{7}$.

La falta de otras fuentes que nos permitan conocer en profundidad la religión ibérica y su dependencia, al menos iconográfica, al mundo mediterráneo oriental, no se agota con estas posibles arquitecturas funerarias. Otros seres fabulosos pululan por el mundo ibérico, destacando la esfinge por encima del resto y las diosas sedentes, cuyo ejemplo más acertado lo hallamos el en la Dama de Baza y quizá alguna de las esculturas sedentes de los santuarios albaceteños de Montealegre (Cerro de los Santos y Llano de la Consolación). En cuanto a la iconografía de la esfinge y con las reservas que solicita $\mathrm{J}$. Bermejo Herrera, cuando acaba por no comprender cual fue su sentido y su significado; la más que clara localización de la esfinge de Agost como remate de un pilar-estela funerario, con claro sentido apotropaico del recinto, se complementa como vehículo para transportar al difunto. Un ejemplo de este significado se observa en la esfinge de Elche, donde el difunto a la grupa, se acoge sin temor (muy lejos del significado primero que tuvo este animal imaginario), mientras que en la parte delantera observamos una figura femenina recostada y cuyos atributos (flor de loto y alas plegadas), nos llevan a identificarla inmediatamente con esa divinidad única mediterránea, venerada bajo la advocación de distintos nombres, si aceptamos lo que expone Apuleyo en su Historia Natural. Esta "diosa... rectora de la vida y de la muerte" (Rafael Ramos Fernández, 1987), que para el mundo fenicio es Astarté, conduce a la esfinge en esta escultura procedente de algún monumento funerario ilicitano. Dicha diosa fenicia aparece nuevamente asociada a una esfinge en una tumba de Cástulo, de claro sabor orientalizante (el "thymiaterion" hallado parece ser de influencia fenicia), con una datación entre los siglos vill-V a. C., al poseer esta cronología el santuario cercano.

El grifo también aparece en el ajuar del Pozo Moro, en concreto en una copa ática, utilizada, quizás después del ritual funerario de llibación, para cubrir la urna donde se encontraban las cenizas, protegiendo así a éstas. 
Esta mezcla de influencias exteriores encuentra un posible sincretismo en los bronces del cortijo de Maquiz, a los que más arriba hemos hecho referencia. Estos bronces, cuya función sería la de brazos de un carro ritual, simbolizando un lecho funerario, acaban en cabezas de carnivoros, los cuales, para Martín Almagro Gorbea representan lobos. La sustitución del felino por el lobo aluden a un cambio de mentalidad hacia la muerte como suceso inexorable (anteriormente el león era tenido como una representación del renacimiento tras la muerte) y, también, a una proyección aborigen sobre el componente exógeno en los rituales funerarios: la decoración incisa de los brazos es una mezcla de referencias clásicas como hipocampos, tritones y nereidas, junto a indígenas, como son los jabalíes y el propio lobo. Aquí la escena de caza de todos los monumentos funerarios to realizan los lobos contra los jabalíes (al comentar los restos de Porcuna hicimos referencia a la caza de un carnero por un lobo), quedando las figuras humanas reducidas a orantes y a combatientes, montados en los animales (una vez más, el combate pone en evidencia el lugar importantísimo de la clase guerrera dentro de la sociedad ibérica). Estilísticamente, estos lobos, con sus bocas abiertas, colmillos en forma de columnillas y la lengua saliente recuerdan a los leones de Pozo de Moro; pero es aún mayor el continuismo del modelo respecto a la cabeza de león perteneciente al cubo del carro encontrado en la necrópolis de La Joya (Huelva). La antigüedad (s. VII a. C.), lo hace modelo fundamental para las posteriores manifestaciones funerarias; mientras que los brazos procedentes de Maquiz, para M. Almagro Gorbea son del siglo Iv a. de $C$., sin embargo, otros investigadores los retrasan a época helenizante ( $L$. Abad y M. Bendala), J. M. Blázquez los sitúa en el siglo II a. C., por los torques, con los que se asociaban en el yacimiento. El simbolismo funerario del lobo se alude en un texto de Pausanias, donde se nos dice que en Grecia los muertos se envolvían en piel de lobos.

Estos bronces del cortijo de Maquiz (Menjibar, antigua «lliturgi»), nos ofrecen un sincretismo formal y simbólico, rastreable también en esa diosa común a todo el Mediterráneo y cuya representación ibérica a falta de conocer su teónimo, se observa en la escultura sedente encontrada por $F$. Presedo; la cual sigue proyectando más sombras que luces (al igual que buena parte de la cultura ibérica), pues para I. Negueruela se trata de un retrato vivo de la "difunta". Sin embargo, la deposición en la misma tumba de armas, la paloma en la mano y la posición sedente en un trono; todo esto unido al elevado coste que hubo de tener la pieza (realización, transporte), aconsejan pensar en una Tanit ibérica, o si se siguiese a Ivan Negueruela nos encontraríamos con una especie de reina amazona. Esta figura femenina permite poner en relación un culto mediterráneo con una iconografía plenamente griega. 
La última manifestación artística ibérica se produce entre los siglos III1 a. C., ya con presencia romana y cuya influencia se hizo notar también en los ritos funerarios; pese a que en un principio tuviese como fin único el cortar el suministro a las tropas de Anibal durante el desarrollo de la II Guerra Púnica.

Para el desarrollo de esta exposición interesan los llamados relieves de Osuna (reutilizados en la muralla) y más en concreto, la segunda serie, pues pertenecen a dos etapas bien distintas. Una de clara influencia griega, cuya representación alude a una procesión, destacando por el detallismo el relieve de la "auletrix" y otro, plenamente romano, con relieves de carácter de combate y de juegos circenses. Tan diferentes estilos y espacio cronológico parecen indicarnos distintas procedencias, aunque siempre de la necrópolis ursoniense: en la primera nos encontramos figuras procesionales; donde observamos una figura masculina con túnica pero sin velo, ni vaso de ofrendas, haciendo posiblemente referencia a algún sacerdote, jóvenes con vasos de ofrendas, de largos velos y la bella flautista donde destacan su macrocefalia, el mayor cuidado en destacar las faciones y el gran cinturón que ciñe la túnica, con posible significado ritualista desde Pozo Moro, ya resaltado profusamente en la Biblia; junto a este desfile procesional encontramos en un sillar-esquina a dos guerreros enfrentados con el equipamiento ibérico de falcata y escudo alargado y un relieve con forma de triángulo irregular que muestra una heroización ecuestre, posiblemente como remate del monumento turriforme. Por contra, el resto de los sillares, muestran escenas propiamente circenses, como desfile y combate de guerreros ibéricos, junto a ejercicios gimnásticos, como el acróbata o el de la cabeza pisada por la garra de un felino situación parecida a la Pátera de Santiesteban del Puerto (Jaén), ya de época helenística, donde un felino tiene en sus fauces una cabeza humana; aunque para J. M. Blázquez es un mito celta. Pero lo verdaderamente interesante son las imágenes de juegos en un monumento turriforme funerario.

Es en realidad un aporte romano, pero que encuentra paralelos ibéricos en los pueblos del área indoeuropea de la Península (entierro de Viriato), por lo que podemos entender que es un significado funerario propio de los pueblos indoeuropeos. En Roma, según la tradición, se introdujeron por los monarcas etruscos, pues en los relieves de Chusi observamos competiciones ecuestres y gimnastas, danzas y desfiles militares, cuyos significados indican los deseos del pueblo por conjurar los poderes de ultratumba en beneficio del difunto. La espectacularidad borraría este significado con el tiempo; pero su carácter funerario se conserva en estos relieves ursonienses. Por último, se 
encuentran dos relieves en otros tantos sillares-esquinas, donde se conserva una tradición más anterior. Uno es el toro (recordemos el toro de Porcuna), relacionado con la fecundidad «y por lo tanto con la regeneración constante de la vida" (T. Chapa Bunet, 1987). Este significado de fecundidad o, más en concreto, del continuo renacimiento tras la muerte, lo podemos relacionar con otro sillar-esquina, donde un rostro con la boca abierta, posiblemente se relacione con una deidad de esta función, pues desde su cabeza crecen espigas y flores; posiblemente no sería muy desacertado relacionarlo con los ritos eleusianos.

\section{CONCLUSIÓN}

El conocimiento de la religiosidad ibérica y más en lo que hace referencia a las creencias funerarias respecto de su evolución ante posibles influencias exógenas, mediante el estudio de la escultura como única fuente posible, es de un carácter marcadamente especulativo.

La fragmentación y la descontextualización, aun peor esta última, de los diversos restos iconógraficos ibéricos ha llevado a incrementar la tendencia hacia la conjetura, la cual se multiplica por la inexistencia de un soporte literario autóctono, cuya lectura permitiese un conocimiento menos parcial sobre un tema, el religioso, y más concretamente, en el aspecto de las creencias funerarias, de amplia significación en las sociedades, pues como hemos comprobado existió un verdadero ensañamiento con algunos monumentos, lo que da la razón a J. M. Blázquez de la premeditación de estas destrucciones; pero parece que aquí se acaba el consenso historiográfico; pues a partir de este "a sabiendas", las conjeturas se amplian hasta provocar la incomprensión.

Quizás un caso ejemplarizante lo hemos señalado respecto al tratar la significación de la Dama de Baza, cuyos antecedentes los podemos encontrar en el título del trabajo de M. I. Rodríguez López: «La gran diosa madre, señora del Mediterráneo prehelénico" (1980). Pero importa mucho más no aceptar las múltiples referencias arqueológicas sobre las características principales de la religión. Esta referencia se hace respecto a una afirmación de J. M. Blazquez en su libro "Religiones en la España antigua" (1991),en la que caracteriza a la religión ibérica como conservadora en su evolución ${ }^{8}$. Ante

\footnotetext{
8 José María Blázouez. Religiones de la España Antigua, Madrid 1991, pag.25. Extraña más en este insigne profesor, cuando en la pág. 87 nos dice: "se introdujeron ahora cambios fundamentales en la religiosidad".
} 
esta afirmación hemos dirigido estas líneas, para demostrar que la religión es un mecanismo ideológico muy importante para que todo dominio lo utilice como método de perpetuación y que, como en los casos de iconografía con sentido funerario, se amolda a unas relaciones de tipo económico, en este caso concreto a unas relaciones coloniales.

Los descubrimientos arqueológicos en esta materia, pese a ser escasos y complicados en su interpretación, son lo suficientemente expresivos para no obviar que la implantación de una determinada iconografía lleva aparejada también su simbología, aunque aceptamos la prudencia que señala J. C. Barmejo Herrera ${ }^{9}$ para cualquier implantación entre la relación iconografía/simbología. Símbolo y representación no pudieran ser idénticos, mas tampoco se puede rechazar dicha identidad. El cambio de determinados elementos iconográficos de procedencia exógena están indicando, aunque sea epidérmicamente, una evolución religiosa que puede afectar dogmáticamente. Volvemos a la conjetura, puesto que los hallazgos arqueológicos nos hablan de cambios iconográficos sin solucionarnos la lectura simbólica, debiendo recurrir a comparaciones mucho más cercanas temporalmente a nosotros.

Paralelismos religiosos muchos más cercanos nos pueden orientar: el cambio tan intranscendente en los Cristos crucificados de aparecer con tres clavos en vez de los cuatro anteriores; paralelo al efectuado en la Madre-Osuna respecto de su frontalidad, con una mayor relación madrehijo, hablan de un cambio mucho más profundo en la religiosidad y en la mentalidad medieval.

\section{BIBLIOGRAFÍA}

Abad, Lorenzo y Bendala, Manuel. El Arte ibérico (Madrid, 1989).

Álvarez, Arturo. El mito de /sis. (Madrid, 1981).

BALLART, Josep. El patrimonio histórico y arqueológico: valor y uso. (Barcelona, 1997).

BENDALA GaLAN, Manuel. Introducción al arte ibérico. (Madrid, 1992).

Bermejo Barrera, José Carlos. Mitología y mitos de la Hispania Prerromana, l. (Torrejón de Ardoz, 1994).

Blázquez Martinez, José Maria. Religiones en la España antigua. (Madrid, 1991).

BRu, Margarita. Iconografia y simbología de las serpientes en la España Antigua. (Madrid, 1988).

Caro Baroja, Julio. El Carnaval. (Madrid, 1979).

DeliBes, Germán. El megalitismo ibérico. (Madrid, 1992).

Dominguez Monedero, Adolfo L. La presencia griega en la Peninsula lbérica. (Madrid, 1980).

Garcia Castro, Juan Antonio, et alii. Escuitura ibérica. (Madrid, 1987).

9 J.C. Barmejo Barrera. Mitologia y mitos de la Hispania Romana, I. Cap. III, pags. 33-38 (Torrejón des Ardoz, 1994). 
Garcia-Gelabert Pérez, M.P. y Blazquez Martinez, J.M. El armamento de la necrópolis ibéricas de la alta Andalucia. (Madrid, 1989).

MALDONADO, Luis. Religiosidad popular. (Madrid, 1975).

Negueruela, Iván. La escultura ibérica. (Madrid, 1992).

Pellicer Catalán, M. y Schüle, W. El Cerro del Real (Galera. Granada). Corte Estratigráfico IX (Madrid, 1988).

RODRIGUEZ LÓPEZ, María Isabel. La gran diosa madre, señora del Mediterráneo prehelénico. (Madrid, 1980).

Rodriguez Neila, Juan Francisco. Los juegos circenses. (Madrid, 1985).

Ruiz Bremon, Mónica y SAN Nicolás Pedraz, M. a Pilar. Los Iberos: Aspectos arqueológicos, antropológicos y médicos (en prensa).

Santos Velasco, Juan A. Contexto funerario en la Cultura lbérica. (Madrid, 1980).

SANTOS Yaguas, Juan A. Los pueblos de la España Antigua. (Madrid, 1989). 